\title{
REGIONAL INTEGRATION PROCESSES AT THE HIGH EDUCATION SYSTEM OF KAZAKHSTAN
}

\author{
Almakul Abdymomynova (PhD), \\ Ulzhan Berikbolova (MA)
}

Kyzylorda State University/Korkyt Ata, Kazakhstan

\begin{abstract}
National systems of the higher education are considerably transformed, gain the increasing similarity, but it occurs taking into account specifics of the social device, economy, policy, pedagogical traditions of this or that country. In the organization and the maintenance of the higher education components of supranational universal property arise and develop. As indicators of this process similar changes in structure, the contents and methods of the higher education. Factors and the purposes of internationalization of the higher education can be distributed on four main groups: economic, political, cultural and pedagogical.
\end{abstract}

Keywords: Region, internationalization, integration, cooperation, education

\section{Introduction}

Basis of development of market economy is division, specialization of managing subjects on production of separate types of the benefits (products, services and works) and coordination integration (cooperation, collaboration) economic activity on achievement of the joint collective purposes.

Division of labor and specialization demands an appropriate level of integration and cooperation. Specialization and integration is the two parties of one phenomenon. Between them exist dialectic reasonable - investigative interconnection and inter conditionality. Progress in division of labor promotes development of integration processes.

«Integration, write P. - F.Gonidek and R. Sharven is at the same time process and the state including a tendency to replacement of the shattered international relations, consisting of the independent units, the new more or less broad associations allocated with the minimum powers to make decisions in one or several areas, or in all areas which enter competence of basic units. At the level of individual consciousness integration is urged to generate loyalty and commitment to new association, and at structural level - 
participation of everyone in its support and development" [Bukin L.2002, p.23].

\section{Main Text}

The objective economic basis for broad development of specialization and integration is created by scientific and technical progress. They take various forms: international, regional, intersectional, intra-branch. Integration increases efficiency of work thanks to that at addition of forces of participants of cooperation there is qualitatively new collective productive force. There is an effect whole (synergetic effect) from interaction and cooperation. Thanks to it becomes possible to provide production of the public benefits, that is the benefits satisfying public, collective needs of people. In economic science on nationality the concept of treatment of integration as public benefits (international and regional) acquires in recent years the right. So fundamental knowledge and monuments of world culture, environmental protection on a planet (prevention of expansion of ozone gaps in the terrestrial atmosphere), maintenance of the uniform world market and uniform world trade economic space, a preservation of peace and safety on the earth, a satellite communication system, the Internet and so on are examples of the international public benefits.

It is possible to carry to the international public benefit and the international cooperation in the field of education through the relevant international institutes (UNESCO, IOM, WHO) and their educational programs, through the international programs of the European Union and via the mechanism of implementation of bilateral contracts on cooperation in the field of science and education at the level of the countries and separate universities.

Existence of any state always assumes interaction with others. This interaction - the fundamental principle of the international relations. Spheres and the directions of the international cooperation are as though diverse were and is as though great there was their value, the central and most important point of the international cooperation remains political. The solution of problems of interaction in many respects depends on its efficiency in other spheres.

Integration processes can be limited to national and regional (local) scales. In this case it is a question about national and the regional public benefits. Integration examples in the sphere of the higher education as the public benefit consumed in national scale, are nation-wide guarantees of receiving by citizens of education, a uniform state policy in the field of education the state educational standard, a uniform state order of social support of teachers and students of the higher school, a uniform order of the state accreditation and licensing of higher education institutions, the central 
government bodies of management of education, republican standards of financing of the higher education, the state control of quality of education, financing of training of students at the expense of the state grants.

At the same time there are the regional public benefits caused by integration processes at the higher school in scales of the region. It is a question of a regional component of the state educational standard and of financing within this component and training of specialists from means of regional and local budgets, of regional state and public governing bodies of education. As a rule, localization of benefits from the public benefit gains territorial character.

Among the most obvious manifestations of the main regularities of the international relations most the importance at the present stage was got by the integration and disintegration factor, observed today everywhere. The tendency of integration represents higher level of interaction between the states when participants of this process alienate part of the sovereignty in favor of supranational bodies. Both that and another, opposite to the first tendency reflect an objective condition of world system in this stage, uncertain nature of its development.

National systems of the higher education are considerably transformed, gain the increasing similarity, but it occurs taking into account specifics of the social device, economy, policy, pedagogical traditions of this or that country. In the organization and the maintenance of the higher education components of supranational universal property arise and develop. As indicators of this process similar changes in structure, the contents and methods of the higher education (open education, distance learning and etc.) act.

Factors and the purposes of internationalization of the higher education can be distributed on four main groups: economic, political, cultural and pedagogical. The first are closely connected with sure financial gains, for example, thanks to a tuition fee of foreign students. Even more important indirect economic benefits as high quality of training of graduates of the higher school appears one of conditions of economic progress. Political factors are generated by geopolitical interests of each country. Cultural follow first of all from intentions of promoting of national culture and familiarizing with foreign-language cultures. And, at last, pedagogical factors are concerned with requirements of modernization of the higher education.

The specific situation develops in the countries where appearing shortage of specialists for the higher school (Australia, Canada) is felt. Here mass recruitment moves to the forefront from abroad cases of teachers. For example, in Canada foreigners make to $25 \%$ of teachers of higher educational institutions. 
All listed factors are developing. At the beginning they were concerned first of all with policy of strengthening of mutual understanding between the people, preservations of cultural influence in developing countries. Then economic priorities become more important. It was reflected, in particular, by the Memorandum of the higher education, accepted by participants of the European Union (1992). The political, pedagogical and cultural goals which follow from intentions to improve preparation of human resources for the successful competition on the international economic scene are subordinated to the specified priorities.

The integration of the higher education appears means of strengthening of economic competitiveness in the world market. Strengthening of the importance of economic factor causes creation of rather mass systems of the higher education and at the same time relative reduction of their financing. Internationalization of the higher education helps with this situation to the solution of economic problems of higher education institutions.

The main directions of internationalization of the higher education are focused on: association of pedagogical efforts and resources; promoting of ideals of mutual respect; education improvement due to the international experience; employment of experts with the higher education on the international labor market; formation at graduates of higher educational institutions of qualities and the knowledge necessary for functioning outside own country. Mobility of students and teachers is encouraged, scales of learning of foreign languages and cultures extend, training programs and diplomas approach.

Thanks to achievements of technological revolution direct contacts, trips of students and teachers are supplemented or replaced with virtual mobility by means of the latest technical means [Galagan A., 1994, p.14]. Communicative technologies, distance learning allows to make the international cooperation of universities more different formatively and intensive.

In Kazakhstan in the period of market economy at the higher school interaction of two tendencies - on the one hand, a tendency of integration, centralization and preservation of uniform educational space, and on the other hand, a tendency to regionalization and decentralization was observed.

The progressive tendency of development of a fundamentalization of the higher education was shown at the Kazakhstan higher school in various forms of integration. I passed process of streamlining of the nomenclature of specialties and the direction of training of specialists. University education gained priority development. Work on optimization of a network of higher education institutions, integration of existing higher education institutions and to creation of regional high school complexes was carried out. 
Cooperation process between the leading high school centers and regional higher education institutions on the basis of coordination and mutual coordination of curricula and programs amplified. There is also an expansion of availability of the high school centers for citizens from regions with insufficiently developed network of educational institutions. It is promoted by development of target preparation and creation of social guarantees for non-residents in realization of the rights to the higher education (preferential journey, preferential terms of accommodation in a hostel and using other objects of high school infrastructure). Extending participation in support and development of public sector of the higher school of authorities of various levels. Increased a role of system of preparation and professional development of scientific and pedagogical shots, and also scientific and methodical providing in the high school centers for peripheral higher education institutions. The effect of integration is provided, on the one hand, due to use of scientific and personnel potential and scientific and experimental base of academic institutions for the purpose of improvement of quality of educational process in higher education institutions, and on the other hand - by creation of branches of chairs of the academic institutes, formation of scientific parks of the higher school. Deepening of integration processes expansion of independence of higher education institutions in the field of the international and university scientific and technical cooperation promotes in no small measure and removal of former regulatory restrictions in the field of combining jobs of scientific and pedagogical shots, and also.

The integration processes at regional and international level in the higher education are the public benefit, but the ratio of benefits and expenses by their granting in many respects depends on a concrete socio-political and economic situation in the respective country. Therefore the analysis both positive, and negative sides of development of various forms of integration in the higher education of Kazakhstan in modern conditions on the example of the concrete region and concrete higher education institution is extremely important. It will give the chance to generalize more deeply positive experience of the solution of problems of integration in the higher school and to make reasonable recommendations about further improvement of cooperative communications in the higher education.

The research of a regional role of the higher school has to be based on definition of the concept "region", its borders of rather physical space and system of interconnections between the economic subjects located in its limits.

The processes of territorial differentiation of production happen in interrelation with integration tendencies in economy. Specialization causes the necessity of strengthening of communications between them as all set of the necessary products, goods, services it is possible to provide with only 
cumulative activity of many regions. At the same time, separate branches and territorial educations are included in a uniform economic complex as its component with specific functions peculiar to them. Along with functional specifics they possess also reproduction features. Therefore it is expedient to consider regions from positions of the general methodological approach to understanding of territorial development and development separate administrative and territorial units.

The region as territorial unit can be characterized by unity of two of its parties: a certain territorial and branch set and organic part of the uniform economic complex including branches of industrial production, services sector, their infrastructure.

As the region we can observe large economic regions, territorial industrial complexes, administrative and territorial units, etc. The region objectively possesses some relative independence within uniform process of reproduction. Each territorial complex has to in every possible way and develop comprehensively own economy, the social sphere and form infrastructure corresponding to them.

The concept of regionalization of education has semantic "wash- out" as it is analyzed on separate various aspects, including economic, pedagogical, national and cultural. Complete understanding as independent part of a component of a uniform social and economic regional complex it isn't developed yet, significant regional internal communications of education aren't allocated. The variety of a tendency of development of regions complicates the solution of problems of determination of properties of education as a part of regional complexes.

The mean of regional educational systems consists that those can be in the presence of the following main signs:

- Sufficient level of development of the educational system, allowing satisfying the corresponding requirements of the population and economy for a mode of differentiation of educational services;

- Abilities of educational system to reflect specifics of local requirements for multidimensional social and pedagogical space in the functioning;

- The presence of the subject of management by education creating round branched system and providing the center of regional educational space.

The understanding regional education systems is expressed that at all levels of its functioning priority there are the tasks directly connected with satisfaction of educational needs of this region. The regional education system also has to be closely connected with all-social, world interests and development tendencies that are the most important conditions of 
preservation of integrity, stability and continuity of an education system and the prerequisite to its entry into world educational system.

The importance of regional aspect of an education system seems that the region acts as the guarantor of steady political resolution of conflicts of development in the state and personality relations, giving the chance to citizens on the basis of the uniform principles in a favorable, available mode to use material, intellectual, educational, social values. Thus the resource financial security of expenses guaranteed by the state on the standardized education level remains.

Regionalization of an education system acts as a condition of its selfdetermination and self-sufficiency. On this background education system interaction with various parties of activity of the region giving, on the basis of feedback, an education system individual and personal and social sense is carried out. Individual and personal interest of subjects of the region is shown in creation material a condition for satisfaction of humanistic, educational, cultural inquiries of subjects of the region; a variety, within the region, opportunities of a regional labor market; formation social relation.

The public importance of education including the professional is defined by that circumstance that if in regional economic system the emphasis on development of any specific branch of economy is placed, it doesn't mean that all specialization in educational system has to be interfaced to economic specialization. The educational system assumes replaceable function of completion and expansion of knowledge of variety of economic structures, communications and the relations, creating conditions for versatile development of the social sphere as a whole and education systems in particular. Impact of a regional education system on development of society is shown by means of the social order to educational system which in turn develops a social environment, forming its information base, stimulating economic transformations, developing prerequisites of free development of subjects of the region. Socialization of the personality in the conditions of the region becomes result of this process.

Promoting development of individual and personal creative abilities there is an education by an indispensable condition of accumulation of professional potential in the region. Education acts as the prerequisite of social development of society by means of self-development of his individuals.

The education system as a systematizing component of social system as training creates economic prerequisites of social transformations and promoting development of the personality in the course of finding of knowledge. The personality in process of growth and development of creative opportunities realizes sense of education not only as means, but also in the form of the purpose. High level of intellectual and spiritual 
development of societies is a continuation of a tendency of perception of education as practical usefulness and economic category.

Deepening and expanding knowledge level, the personality not only requests, but also builds under the inquiry elements of a social environment. Education in the conditions of the region, acting as objective requirement of social and scientific and technical development becomes a factor of regional development.

However professional education can't be expelled from system economic categories. It forms a basis of development of abilities of the person to work that conducts to need of consideration it with economic positions.

\section{Conclusion}

Consideration of essence of a regionalism of education leads to a conclusion that process of regionalization includes consecutive orientation of activity of educational institutions of various profile and level to needs of the region with their subsequent inclusion in social and economic system of the region. As backbone elements of regionalization of education act orientation to the needs of the personality realized in the concrete social environment: formation of uniform educational space of the region; the accounting of concrete features of the region at the organization of activity of an education system; development of spheres and directions of vigorous activity of an education system; development of structure of training programs and the courses focused on studying of natural, geographical, cultural, national, industrial, historical, ethnic features of the region.

\section{References:}

Bukin L.L. Regionalnya podsystema vyshego obrazovanya: voprosy socyany-ekonomysheskogo razvytya.- Sankt Peterburg, 2002

Galagan A.I. Yniversyteti v regionalnyh ekonomysheskyh I ypravlensheskyh stryktyrah USA, stran Zapadnoy Europe,Japan- Moscow, 1994

Bogachev E.N. Metodologya novogo hozyastvennogo mehanyzma v vyshyh uchebnyh zavedenyah v uslovyah rynka. - Moscow,1990

Grynchel B.M. Osnovy regyonalny ekonomycy-Moscow,2000

Organization for economic cooperation and development. Statistics and publications. www.oecd.org 